\title{
Female sex and food insecurity in relation to self-reported poor or fair mental health in Canadian adults: a cross-sectional study using national survey data
}

\author{
Catherine M. Pound MD MSc, Yue Chen MD PhD
}

\section{Abstract}

Background: Women with food insecurity are at higher risk for mental health disorders. This study examined the joint effect of female sex and food insecurity on self-reported poor or fair mental health in Canadian adults.

Methods: The analysis was based on data from adults (age $\geq 18 \mathrm{yr}$ ) who participated in the Canadian Community Health Survey (CCHS) 2015-2016. We determined past-year food security level (secure, moderately insecure or severely insecure) based on 18 questions. We used log-binomial regression to explore associations of sex and food insecurity with self-reported poor or fair mental health. We measured additive interaction between female sex and food insecurity using relative excess risk due to interaction (RERI).

Results: The overall response rate for the CCHS was 59.5\%. Data for 61446 respondents were analyzed. Poor or fair mental health was reported by 4107 participants $(6.1 \%$ when weighted to the Canadian population). Increased risk of poor or fair mental health was associated with female sex (prevalence ratio [PR] 1.22, 95\% confidence interval [Cl] 1.12 to 1.31), and moderate (PR 2.50, 95\% Cl 2.21 to 2.82) and severe (PR 4.03, 95\% Cl 3.59 to 4.52) food insecurity. Significant additive interaction between female sex and severe food insecurity was found for those aged 40-64 years (RERI 1.38, 95\% Cl 0.29 to 2.47 ), and the PR for poor or fair mental health for severely food-insecure women was 5.55 (95\% $\mathrm{Cl} 4.48$ to 6.89$)$ compared to food-secure men of the same age group.

Interpretation: Poor or fair mental health is common in the food-insecure population, and there exists synergism between female sex and severe food insecurity among middle-aged people. This suggests the need to develop targeted mental health support strategies for food-insecure people, specifically middle-aged women.

$\mathrm{F}$ ood insecurity is defined as the "inability to acquire or consume an adequate diet quality or sufficient quantity of food in socially acceptable ways, or the uncertainty that one will be able to do so." ${ }^{1}$ In Canada, about $8 \%-12 \%$ of households are reported to experience food insecurity ${ }^{2,3}$ secondary to financial constraints. Food insecurity is linked to poverty, single-parent household status, reliance on social assistance, ${ }^{4}$ low educational attainment ${ }^{5}$ and smoking. ${ }^{6}$ Food insecurity may increase the risk of multiple adverse health consequences, including malnutrition secondary to nutrient inadequacies, ${ }^{7}$ diabetes ${ }^{8}$ cardiovascular disease ${ }^{9}$ and obesity. ${ }^{10}$ In addition, significant associations have been reported between food insecurity and mental health disorders, specifically mood and anxiety disorders. ${ }^{411}$ One Canadian study reported a prevalence of mental illness of $35 \%$ among those with food insufficiency, ${ }^{12}$ in contrast to a prevalence of about $10 \%$ in the general Canadian population. ${ }^{13}$
Women have been described to be at increased risk compared to men for poor mental health in relation to food insecurity ${ }^{4,14}$ irrespective of educational attainment ${ }^{15}$ and are more likely to experience food insecurity. ${ }^{16}$ In addition, single mothers are disproportionately affected by food insecurity, ${ }^{17}$ with more than one-third of female lone-parent families experiencing food insecurity in Canada in 2014, ${ }^{3}$ which raises concerns for potential negative impacts on children's physical and mental well-being.

Competing interests: None declared.

This article has been peer reviewed.

Correspondence to: Catherine Pound, cpound@cheo.on.ca

CMAJ Open 2021. DOI:10.9778/cmajo.20200112 
We hypothesized that female sex and food insecurity have an additive interaction on perceived self-reported poor or fair mental health in Canadian adults, and our study aimed to examine this joint effect.

\section{Methods}

\section{Data source}

The current study was based on data from the Canadian Community Health Survey (CCHS) 2015-2016. ${ }^{18}$ The CCHS is a cross-sectional survey that gathers information related to the health status and determinants of health of the Canadian population..$^{19}$ It collects data from people aged 12 years or more in all 10 provinces and 3 territories. People living on reserves and other Aboriginal settlements, full-time members of the Canadian Forces, people living in institutions, children aged 12-17 living in foster care, and people living in the Nunavik Region and the Terres-Cries-de-la-Baie-James are excluded from the sampling frame $(<3 \%$ of the target Canadian population). ${ }^{18}$

\section{Study population}

All participating adults (aged $\geq 18 \mathrm{yr}$ ) with data on past-year food security status and perceived poor or fair mental health were included. We selected perceived mental health, as opposed to diagnosed mental health illness, as a health outcome so as to include people who had not received a diagnosis from a health care provider but may still have been experiencing poor or fair mental health. Around $15 \%$ of Canadians do not have a family physician, ${ }^{20}$ which makes access to care difficult for a subset of the population. Estimates based on diagnosed mental health disorders may therefore underestimate the association between food insecurity and mental health illness.

\section{Measurement of mental health}

Five levels of self-reported perceived mental health states (excellent, very good, good, fair and poor) are collected by the CCHS in response to the question "In general, would you say your mental health is ... excellent/very good/good/fair/poor/ don't know/refusal/not stated." ${ }^{11}$ We focused on the group who reported poor or fair mental health.

\section{Combined exposure of food insecurity and sex}

The variable used in our study - household food security status - was adopted from the Health Canada model of food security status levels published in 2007.22 This variable is based on a set of 18 questions and describes the food security situation of the household in the previous 12 months. It captures 3 kinds of situations: food secure ( 0 or 1 indication of difficulty with income-related food access), moderately food insecure (indication of compromise in the quality or quantity, or both, of food consumed) and severely food insecure (indication of reduced food intake and disrupted eating patterns). ${ }^{21}$ To determine the effect of the joint exposure of sex and food security, we grouped participants into 6 categories: male and food secure, male and moderately food insecure, male and severely food insecure, female and food secure, female and moderately food insecure, and female and severely food insecure. We used the "male and food secure" group as the reference.

\section{Covariates}

We performed a MEDLINE search of the literature to identify factors known to be associated with food insecurity ${ }^{4-6,17,23-25}$ as well as factors associated with mental health issues. ${ }^{26-28} \mathrm{We}$ chose factors associated with both for which data were available in the CCHS survey as covariates for our study. These included age (early adulthood [18-39 yr], middle age [40-64 yr], older age [ $\geq 65 \mathrm{yr}]$ ), marital status (married or common-law; widowed, divorced, separated or single), number of household members $(1-2,3-4, \geq 5)$, educational level (less than secondary school, secondary school completed, more than secondary school) and smoking status (current smoker [daily or occasionally], former smoker, nonsmoker).

\section{Statistical analysis}

We used descriptive statistics to describe the distributions of the outcome, exposure of interest and covariables. We used the $\chi^{2}$ test for group comparisons, using $p$ values accounting for the complex survey design. We determined population weighting as follows. We calculated a relative weight for each participant that was the sampling weight (provided by Statistics Canada) divided by the average weight of included participants. We determined an adjusted weight by dividing the relative weight by the square root of the average design effect of the CCHS survey. We used log-binomial regression to determine the prevalence of perceived poor or fair mental health associated with sex and food insecurity, taking potential confounding factors into consideration and stratified the estimates for the joint exposure of sex and food insecurity by age. We calculated crude and adjusted prevalence ratios (PRs) and their $95 \%$ confidence intervals (CIs).

To measure the additive interaction between female sex and food insecurity in association with perceived poor or fair mental health, we calculated relative excess risk due to interaction (RERI), attributable portion due to interaction (AP) and synergy index (S) and their respective 95\% CIs. ${ }^{29}$ Relative excess risk due to interaction measures the proportion of increased risk for poor or fair mental health due to the interaction of female sex and food insecurity relative to the risk without exposure to either factor, AP measures the proportion of poor or fair mental health due to the interaction of both factors, and $\mathrm{S}$ measures the excess risk from the interaction relative to the excess risk expected without an interaction (sum of individual effects). Age was found to be an effect modifier at a $p$ level of $<0.05$, and, therefore, we provided age-specific additive interaction measures.

To account for the complex survey design (stratified and cluster sampling with unequal selection probabilities), we used adjusted weights that were calculated based on sampling weights and average design effect, for all the point and variance estimations.

Survey respondents who did not provide information on food security status or perceived poor or fair mental health were excluded. We performed listwise deletion for covariates 
with missing values of less than $1 \%$. We performed all statistical analyses using SAS 9.4 software (SAS Institute).

\section{Ethics approval}

Ethics approval was not required for this study.

\section{Results}

A total of 61446 participants were included in the analysis. Initially, 61782 survey respondents had data available for the exposure (sex and food security status) and the outcome (perceived poor or fair mental health) of interest. Smoking status was missing for 151 respondents, marital status for 147 and household size for 38 . We created an additional category of "unknown" for education level, since 701 respondents (1.1\%) had missing data for this variable (Figure 1). The overall response rate for the CCHS 2015-2016 was 59.5\%. ${ }^{19}$

\section{Perceived poor or fair mental health}

Table 1 shows the prevalence of perceived poor or fair mental health and the distribution of food security status. Overall,
4107 participants (6.1\%) reported perceived poor or fair mental health, and 5332 (7.6\%) reported some degree of food insecurity. The prevalence of perceived poor or fair mental health increased with the level of food insecurity, more so for women (food secure 5.3\%, moderately food insecure $15.6 \%$, severely food insecure $32.5 \%)$ than men $(4.5 \%, 14.4 \%$ and $25.2 \%$, respectively). The prevalence of perceived poor or fair mental health and the distribution of food security status by age are presented in Appendix 1 (available at www.cmajopen. ca/content/9/1/E71/suppl/DC1).

\section{Association of sex and food security status with perceived poor or fair mental health}

Table 2 summarizes adjusted PRs for sex and food insecurity in association with self-reported poor or fair mental health. Overall, the prevalence of perceived poor or fair mental health was significantly higher among women than among men (PR 1.22, 95\% CI 1.12 to 1.31) and among those with moderate (PR 2.50, 95\% CI 2.21 to 2.82) or severe (PR 4.03, $95 \%$ CI 3.59 to 4.52 ) food insecurity compared to those without food insecurity. The adjusted PR for perceived poor or

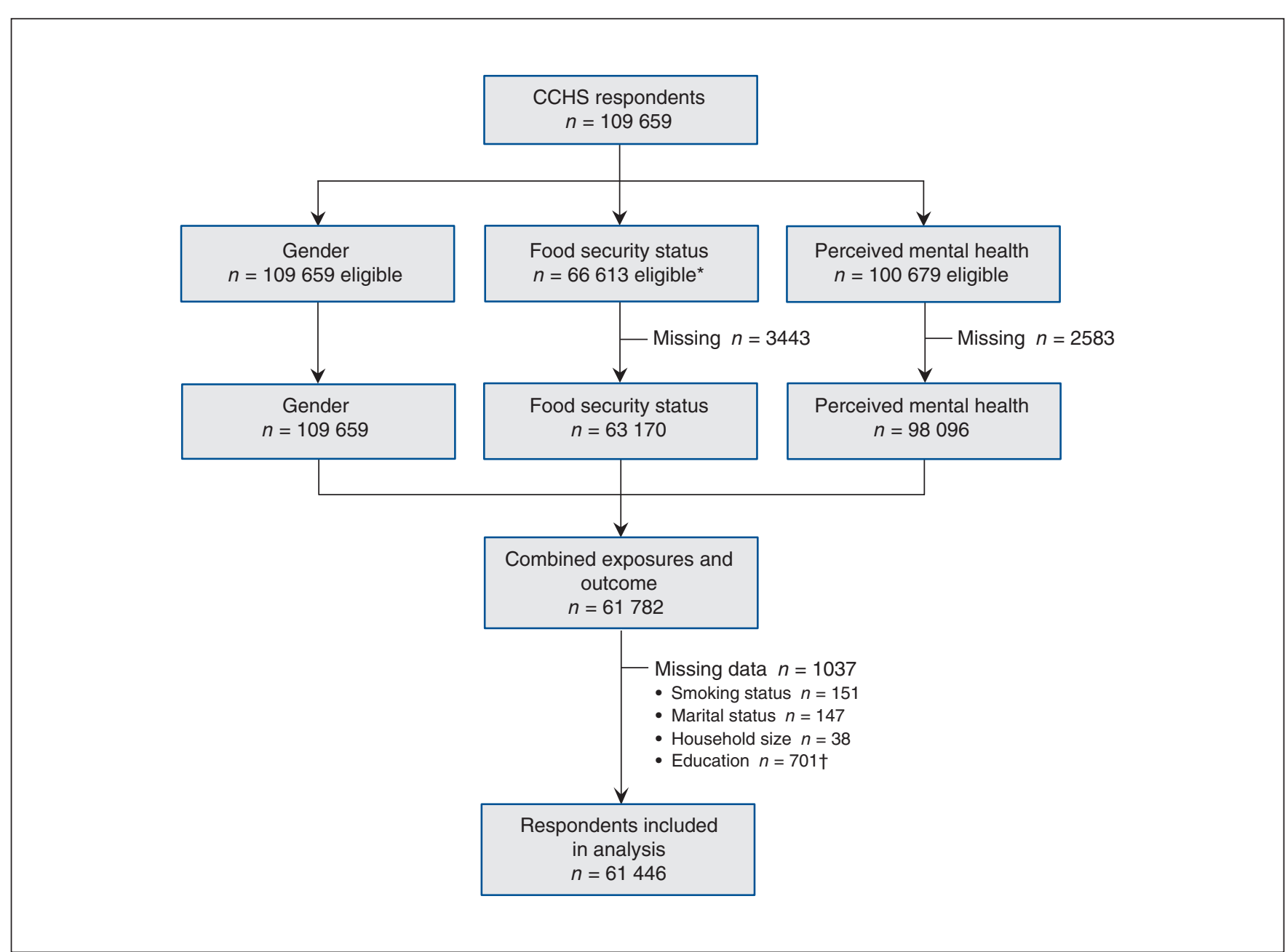

Figure 1: Flow diagram showing selection of study participants. *Respondents aged 12-17 years were excluded when a most knowledgeable person was not identified. †Retained as "unknown" category. Note: CCHS = Canadian Community Health Survey. 


\begin{tabular}{|c|c|c|c|c|}
\hline \multirow[b]{2}{*}{ Characteristic } & \multicolumn{2}{|c|}{ No. of respondents } & \multirow[b]{2}{*}{$\begin{array}{c}\text { Prevalence, } \\
\%\end{array}$} & \multirow[b]{2}{*}{$p$ value } \\
\hline & $\begin{array}{c}\text { Overall } \\
n=61446\end{array}$ & $\begin{array}{l}\text { With perceived } \\
\text { poor or fair } \\
\text { mental health } \\
n=4107\end{array}$ & & \\
\hline Food security status & & & & $<0.001$ \\
\hline Food secure & 56114 & 2907 & 4.9 & \\
\hline Moderately food insecure & 3189 & 540 & 15.1 & \\
\hline Severely food insecure & 2143 & 660 & 29.3 & \\
\hline Sex & & & & 0.007 \\
\hline Male & 28000 & 1788 & 5.4 & \\
\hline Female & 33446 & 2319 & 6.7 & \\
\hline Food security status and sex & & & & $<0.001$ \\
\hline Male and food secure & 25894 & 1326 & 4.5 & \\
\hline Male and moderately food insecure & 1215 & 201 & 14.4 & \\
\hline Male and severely food insecure & 891 & 261 & 25.2 & \\
\hline Female and food secure & 30220 & 1581 & 5.3 & \\
\hline Female and moderately food insecure & 1974 & 339 & 15.6 & \\
\hline Female and severely food insecure & 1252 & 399 & 32.5 & \\
\hline Age, yr & & & & $<0.001$ \\
\hline $18-39$ & 18622 & 1282 & 6.5 & \\
\hline $40-64$ & 25765 & 1949 & 6.3 & \\
\hline$\geq 65$ & 17059 & 876 & 4.8 & \\
\hline Marital status & & & & $<0.001$ \\
\hline Married/common-law & 34299 & 1619 & 4.6 & \\
\hline Widowed/divorced/separated/single & 27147 & 2488 & 8.7 & \\
\hline No. of household members & & & & $<0.001$ \\
\hline $1-2$ & 41782 & 2946 & 6.5 & \\
\hline $3-4$ & 15409 & 914 & 5.7 & \\
\hline$\geq 5$ & 4255 & 247 & 5.0 & \\
\hline Education & & & & $<0.001$ \\
\hline Less than secondary & 9675 & 997 & 9.9 & \\
\hline Secondary completed & 13823 & 932 & 6.1 & \\
\hline More than secondary & 37247 & 2136 & 5.4 & \\
\hline Unknown & 701 & 42 & 5.7 & \\
\hline Smoking & & & & $<0.001$ \\
\hline Current & 12169 & 1411 & 10.7 & \\
\hline Former & 19697 & 1186 & 5.5 & \\
\hline Never & 29580 & 1510 & 4.7 & \\
\hline
\end{tabular}

fair mental health for women experiencing severe food insecurity compared to men with food security was 5.55 (95\% CI 4.48 to 6.89 ) for those aged $18-39,4.94$ (95\% CI 4.06 to 6.02) for those aged 40-64, and 2.97 (95\% CI 1.48 to 5.95) for those aged 65 or more (Table 2).
Additive interaction of sex and food security status in relation to perceived poor or fair mental health

Additive interaction measures are presented in Table 3. Overall, there was significant synergism between female sex and severe food insecurity in association with the risk of 
Table 2: Adjusted prevalence ratios for association of sex and food security status with perceived poor or fair mental health

\begin{tabular}{|c|c|}
\hline Variable & $\mathrm{PR}(95 \% \mathrm{Cl})$ \\
\hline \multicolumn{2}{|c|}{ Individual exposures of sex and food security* } \\
\hline \multicolumn{2}{|l|}{ Sex } \\
\hline Male & Reference \\
\hline Female & $1.22(1.12$ to 1.31$)$ \\
\hline \multicolumn{2}{|l|}{ Food security } \\
\hline Food secure & Reference \\
\hline Moderately food insecure & $2.50(2.21$ to 2.82$)$ \\
\hline Severely food insecure & 4.03 (3.59 to 4.52$)$ \\
\hline \multicolumn{2}{|c|}{ Joint exposure of sex and food security by age $†$} \\
\hline \multicolumn{2}{|c|}{ Overall } \\
\hline \multicolumn{2}{|l|}{ Male } \\
\hline Food secure & Reference \\
\hline Moderately food insecure & $2.65(2.19$ to 3.21$)$ \\
\hline Severely food insecure & 3.78 (3.17 to 4.51$)$ \\
\hline \multicolumn{2}{|l|}{ Female } \\
\hline Food secure & $1.20(1.10$ to 1.32$)$ \\
\hline Moderately food insecure & $2.91(2.49$ to 3.41$)$ \\
\hline Severely food insecure & 5.05 (4.39 to 5.82$)$ \\
\hline \multicolumn{2}{|l|}{ Age 18-39 yr } \\
\hline \multicolumn{2}{|l|}{ Male } \\
\hline Food secure & Reference \\
\hline Moderately food insecure & 2.11 (1.52 to 2.92$)$ \\
\hline Severely food insecure & 4.15 (3.19 to 5.40$)$ \\
\hline \multicolumn{2}{|l|}{ Female } \\
\hline Food secure & $1.43(1.22$ to 1.66$)$ \\
\hline Moderately food insecure & $3.48(2.79$ to 4.34$)$ \\
\hline Severely food insecure & 5.55 (4.48 to 6.89$)$ \\
\hline \multicolumn{2}{|l|}{ Age 40-64 yr } \\
\hline \multicolumn{2}{|l|}{ Male } \\
\hline Food secure & Reference \\
\hline Moderately food insecure & 3.13 (2.43 to 4.03$)$ \\
\hline Severely food insecure & 3.42 (2.63 to 4.44$)$ \\
\hline \multicolumn{2}{|l|}{ Female } \\
\hline Food secure & 1.14 (0.99 to 1.32$)$ \\
\hline Moderately food insecure & 2.56 (1.99 to 3.28$)$ \\
\hline Severely food insecure & 4.94 (4.06 to 6.02$)$ \\
\hline \multicolumn{2}{|l|}{ Age $\geq 65 y r$} \\
\hline \multicolumn{2}{|l|}{ Male } \\
\hline Food secure & Reference \\
\hline Moderately food insecure & 3.79 (2.03 to 7.06$)$ \\
\hline Severely food insecure & 5.80 (3.02 to 11.11$)$ \\
\hline \multicolumn{2}{|l|}{ Female } \\
\hline Food secure & $0.94(0.74$ to 1.20$)$ \\
\hline Moderately food insecure & $2.13(1.19$ to 3.80$)$ \\
\hline Severely food insecure & 2.97 (1.48 to 5.95$)$ \\
\hline \multicolumn{2}{|c|}{$\begin{array}{l}\text { Note: } \mathrm{Cl}=\text { confidence interval, } \mathrm{PR}=\text { prevalence ratio. } \\
\text { *Variables included in the model were sex, food security status, age, education, } \\
\text { marital status, smoking and household size. } \\
\text { tVariables included in the models were the combination of sex and food security } \\
\text { status, age (overall model only), education, marital status, smoking and } \\
\text { household size. }\end{array}$} \\
\hline
\end{tabular}

perceived poor or fair mental health. When stratified by age, the synergistic effect was significant only for women aged 40-64 years (RERI $1.38,95 \%$ CI 0.29 to 2.47 ; AP $0.28,95 \%$ CI 0.09 to 0.47 ; S $1.54,95 \% 1.07$ to 2.21 ) (Figure 2).

\section{Interpretation}

The prevalence of perceived poor or fair mental health in the current study was much higher in the moderately and severely food-insecure groups (15.1\% and $29.3 \%$, respectively) than in the food-secure group (4.9\%). We observed an association between food insecurity and perceived poor or fair mental health in all age categories studied. In addition, for either level of food insecurity, point estimates of association measures were higher among females than among males, except for older adults.

The observed protective effect of age in women is interesting. It could be that older women typically do not have children living with them and therefore no longer need to worry about providing food for them, which would relieve some of the stress associated with food insecurity. We found an additive interaction between female sex and food insecurity, which suggests a synergistic effect on perceived poor or fair mental health. This synergism was significantly modified by age: when the results were stratified by age, an additive interaction between female sex and severe food insecurity was identified among those aged 40-64. There was a substantial increase in excess risk of perceived poor or fair mental health due to this interaction for women aged 40-64 years with severe food insecurity relative to the risk for food-secure men of the same age bracket.

The observed dose-response relation between severity of food insecurity and the risk of poor or fair mental health is consistent with a previous report. ${ }^{12}$

Given the cross-sectional nature of the CCHS, the directionality of the relation between food insecurity and poor or fair mental health cannot be established with certainty. Although the chronic stress of food insecurity is thought to lead to poor mental health outcomes, ${ }^{30}$ it is conceivable that poor mental health may result in food insecurity, owing to the impact of poor mental health on a person's ability to maintain financial stability or manage a household. ${ }^{31}$

The observed additive interaction between female sex and food insecurity is consistent with previous reports showing that women are at greater risk for mental health issues in relation to food insecurity., ${ }^{4,15}, 16$ Although the reason for this is unclear, it has been postulated that the chronic stress of food insecurity may be felt predominantly by women, as they often are the ones responsible for food preparation in a household. ${ }^{30}$ The additive interaction was less marked in the younger age group (18-39 yr) and absent in the older age group ( $\geq 65 \mathrm{yr}$ ).

In a recent review of 31 studies of food insecurity and mental health in women in high-income countries, Maynard and colleagues ${ }^{4}$ noted the paucity of research focusing on older women. However, our study highlights the association of female sex and food insecurity in relation to poor or fair 


\begin{tabular}{|c|c|c|c|}
\hline \multirow[b]{2}{*}{ Exposure category } & \multicolumn{3}{|c|}{ Additive interaction measure $(95 \% \mathrm{Cl})$} \\
\hline & RERI & AP & Synergy index \\
\hline \multicolumn{4}{|l|}{ Overall } \\
\hline Severe food insecurity female v. male sex & 1.07 (0.24 to 1.89$)$ & $0.21(0.06$ to 0.36$)$ & $1.36(1.06$ to 1.74$)$ \\
\hline Moderate food insecurity female v. male sex & $0.05(-0.57$ to 0.68$)$ & $0.02(-0.20$ to 0.23$)$ & $1.03(0.74$ to 1.44$)$ \\
\hline \multicolumn{4}{|l|}{ Age, yr } \\
\hline \multicolumn{4}{|l|}{ 18-39 } \\
\hline Severe food insecurity female v. male sex & $0.97(-0.38$ to 2.33$)$ & $0.18(-0.05$ to 0.40$)$ & 1.27 (0.90 to 1.79$)$ \\
\hline Moderate food insecurity female v. male sex & $0.95(0.02$ to 1.87$)$ & $0.27(0.04$ to 0.51$)$ & $1.62(0.97$ to 2.70$)$ \\
\hline \multicolumn{4}{|l|}{$40-64$} \\
\hline Severe food insecurity female v. male sex & $1.38(0.29$ to 2.47$)$ & $0.28(0.09$ to 0.47$)$ & 1.54 (1.07 to 2.21$)$ \\
\hline Moderate food insecurity female v. male sex & $-0.72(-1.65$ to 0.22$)$ & $-0.28(-0.68$ to 0.12$)$ & $0.68(0.42$ to 1.11$)$ \\
\hline \multicolumn{4}{|l|}{$\geq 65$} \\
\hline Severe food insecurity female v. male sex & $-2.7(-6.93$ to 1.40$)$ & $-0.93(-2.70$ to 0.84$)$ & $0.42(0.12$ to 1.47$)$ \\
\hline Moderate food insecurity female v. male sex & $-1.60(-4.18$ to 0.98$)$ & $-0.75(-2.18$ to 0.68$)$ & $0.41(0.11$ to 1.55$)$ \\
\hline
\end{tabular}

Note: $\mathrm{AP}=$ attributable portion due to interaction, $\mathrm{Cl}$ = confidence interval, $\mathrm{RERI}=$ relative excess risk due to interaction.

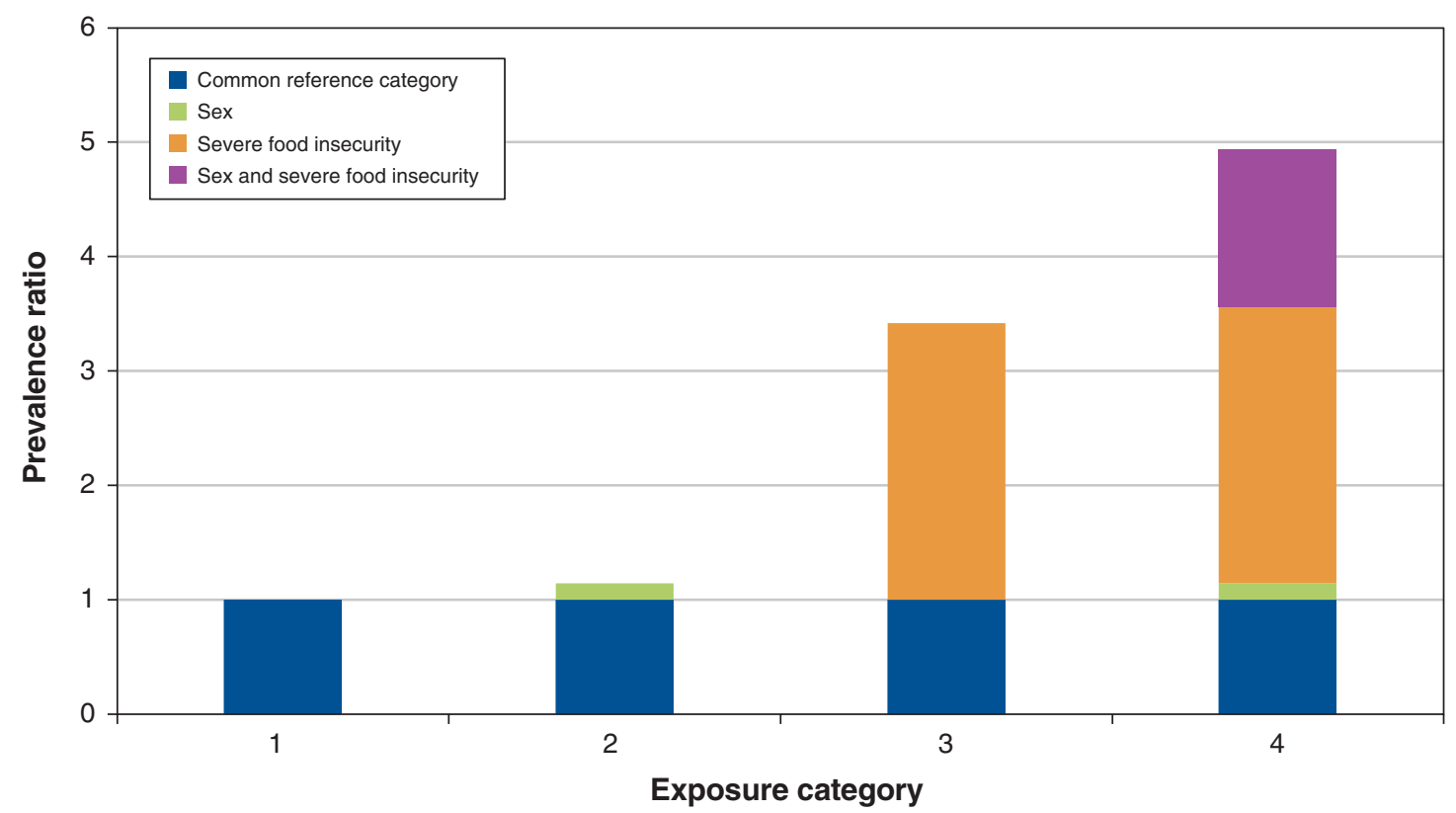

Figure 2: Synergism between female sex and severe food insecurity in association with self-reported perceived poor or fair mental health among respondents aged 40-64 years. Category $1=$ reference, category 2 = risk of poor or fair mental health conferred by sex, category $3=$ risk of poor or fair mental health conferred by severe food insecurity, category $4=$ risk of poor or fair mental health conferred by sex and severe food insecurity combined (additive interaction).

mental health in women aged 40-64 years, which emphasizes the need to develop interventions targeted to this age group. This synergism of female sex and food insecurity also has implications for children's health, since maternal mental health is known to affect children's development ${ }^{32,33}$ and many women aged 40-64 are of child-rearing age. In addition, 
research focusing on older women affected by food insecurity would be helpful to explore potential resiliency factors that may confer a protective effect.

Given the current novel coronavirus situation and the very unstable financial climate, the prevalence of moderate and severe food insecurity is likely to increase substantially over the next few months, which may result in an even higher burden of mental health issues in this subset of the Canadian population. There is therefore an urgent need to continue raising awareness regarding the prevalence of mental health illnesses in food-insecure people.

\section{Limitations}

The overall response rate was relatively low for the CCHS. This may have affected the magnitude of the relation between food insecurity, sex and poor or fair mental health, as foodinsecure people and those with poor or fair mental health may not prioritize participating in a survey. Aboriginal people living on reserve, who are known to be at high risk for both food insecurity and poor or fair mental health, ${ }^{34}$ are excluded from the CCHS sampling frame. Homeless people, also at greater risk for food insecurity, ${ }^{35}$ are also excluded. Although it is not possible to predict with certainty the direction and magnitude of the impact these groups would have on our results, we hypothesize that their exclusion biases our results toward the null, given the high prevalence of food insecurity and poor or fair mental health in these groups.

The choice of outcome of interest, self-perceived poor or fair mental health (as compared to diagnosed mental health illness), can be considered both a limitation and a strength. Mental health disorders are known to be underdiagnosed in Canada. ${ }^{36}$ Also, although self-reporting of mental health states is not based on any strict criteria, it does allow the inclusion of people with poor or fair mental health that have not been diagnosed owing to a multitude of reasons, including lack of access to care. Although self-reported mental health states cannot be used to assess the prevalence of specific disorders such as depression and anxiety, it allows for broader inclusion of people at risk by potentially identifying clinically unapparent issues.

Finally, because the CCHS is cross-sectional, temporality of the association cannot be established with certainty.

\section{Conclusion}

This study shows the high prevalence of poor or fair mental health in those who are food insecure and highlights the association between food insecurity and perceived poor or fair mental health. It also emphasizes the synergistic effect of female sex and food insecurity, associated with an excess risk of poor or fair mental health, in particular among women aged 40-64 years. Heightened consideration should be given to the development of innovative and far-reaching screening methods, as well as the implementation of strategies to support the mental health of food-insecure people, specifically middle-aged women in light of their heightened risk of poor mental health outcomes in relation to food insecurity.

\section{References}

1. Davis B, Tarasuk V. Hunger in Canada. Agric Human Values 1994;11:50-7.

2. Health at a glance: food insecurity in Canada. Ottawa: Statistics Canada; 2015. Cat no 82-624-X. Available: www150.statcan.gc.ca/n1/pub/82-624-x/2015001/ article/14138-eng.htm (accessed 2020 May 12)

3. Tarasuk V, Mitchell A, Dachner N. Household food insecurity in Canada, 2014. Toronto: Research to identify policy options to reduce food insecurity (PROOF); 2016. Available: https://proof.utoronto.ca/wp-content/uploads/ 2016/04/Household-Food-Insecurity-in-Canada-2014.pdf (accessed 2020 May 12).

4. Maynard M, Andrade L, Packull-McCormick S, et al. Food insecurity and mental health among females in high-income countries. Int 7 Environ Res Public Health 2018;15:1424.

5. Lund TB, Holm L, Tetens I, et al. Food insecurity in Denmark - sociodemographic determinants and associations with eating - and health-related variables. Eur 7 Public Health 2018;28:283-8.

6. Farrelly MC, Shafer PR. Comparing trends between food insecurity and cigarette smoking among adults in the United States, 1998 to 2011. Am 7 Health Promot 2017;31:413-6.

7. Kirkpatrick SI, Tarasuk V. Food insecurity is associated with nutrient inadequacies among Canadian adults and adolescents. 7 Nutr 2008;138:604-12.

8. Gucciardi E, Vogt JA, DeMelo M, et al. Exploration of the relationship between household food insecurity and diabetes in Canada. Diabetes Care 2009; 32:2218-24.

9. Morales ME, Berkowitz SA. The relationship between food insecurity, dietary patterns and obesity. Curr Nutr Rep 2016;5:54-60.

10. Dhurandhar EJ. The food-insecurity obesity paradox: a resource scarcity hypothesis. Physiol Behav 2016;162:88-92.

11. Jessiman-Perreault G, McIntyre L. The household food insecurity gradient and potential reductions in adverse population mental health outcomes in Canadian adults. SSM Popul Health 2017;3:464-72.

12. Muldoon KA, Duff PK, Fielden S, et al. Food insufficiency is associated with psychiatric morbidity in a nationally representative study of mental illness among food insecure Canadians. Soc Psychiatry Psychiatr Epidemiol 2013;48: 795-803.

13. McRae L, O'Donnell S, Loukine L, et al. Report summary - mood and anxiety disorders in Canada, 2016. Health Promot Chronic Dis Prev Can 2016;36: 314-5.

14. Ivers LC, Cullen KA. Food insecurity: special considerations for women. Am $\mathcal{Z}$ Clin Nutr 2011;94:1740S-4S.

15. Koury AJ, Dynia J, Logan JAR, et al. Food insecurity and depression among economically disadvantaged mothers: Does maternal efficacy matter? Appl Psychol Health Well-Being 2020;12:432-48.

16. Maheux H, Chui T. Women in Canada: a gender-based statistical report. Ottawa: Statistics Canada; 2011. Cat no 89-503-X. Available: www150.statcan.gc.ca/n1/ en/catalogue/89-503-X (accessed 2020 May 12).

17. Power M, Uphoff EP, Stewart-Knox B, et al. Food insecurity and sociodemographic characteristics in two UK ethnic groups: an analysis of women in the Born in Bradford cohort. 7 Public Health (Oxf) 2018;40:32-40.

18. Canadian Community Health Survey (CCHS) annual component, study documentation, 2015-2016. Ottawa: Statistics Canada; 2017.

19. Canadian Community Health Survey (CCHS) annual component, user guide. Microdata file. Statistics Canada; 2016.

20. Health fact sheets. Primary health care providers, 2017. Ottawa: Statistics Canada; modified 2019 Feb. 21. Cat no 82-625-X. Available: www150.statcan.gc.ca/n1/ pub/82-625-x/2019001/article/00001-eng.htm (accessed 2020 May 12).

21. Canadian Community Health Survey (CCHS): annual component, PUMF, 20152016. Derived variable (DV) specifications. Ottawa: Statistics Canada; 2017.

22. Government of Canada. Canadian Community Health Survey, cycle 2.2, Nutrition (2004): income-related housebold food security. Ottawa: Statistics Canada; modified 2008 Jan. 7. Cat no H164-42/2007E-PDF. Available: www.canada.ca/en/health-canada/services/food-nutrition/food-nutrition -surveillance/health-nutrition-surveys/canadian-community-health-survey -cchs/canadian-community-health-survey-cycle-2-2-nutrition-2004-income -related-household-food-security-canada-health-canada-2007.html (accessed 2020 Aug. 31).

23. McIntyre L, Dutton D, Kwok C, et al. Reduction of food insecurity among low-income Canadian seniors as a likely impact of a guaranteed annual income. Can Public Policy 2016:42:274-86.

24. Ihabi AN, Rohana AJ, Wan Manan WM, et al. Nutritional outcomes related to household food insecurity among mothers in rural Malaysia. 7 Health Popul Nutr 2013;31:480-9.

25. Tarasuk V, Fafard St-Germain AA, Michell A. Geographic and sociodemographic predictors of household food insecurity in Canada, 2011-12. BMC Public Health 2019;19:12.

26. Akhtar-Danesh N, Landeen J. Relation between depression and sociodemographic factors. Int 7 Ment Health Syst 2007;1:4.

27. Singh A, Daniel L, Maker E, et al. Housing disadvantage and poor mental health: a systematic review. Am 7 Prev Med 2019;57:262-72.

28. Plurphanswat N, Kaestner N, Rodu B. The effect of smoking on mental health. Am 7 Health Behav 2017;41:471-83. 
29. Andersson T, Alfredsson L, Källberg H, et al. Calculating measures of biological interaction. Eur 7 Epidemiol 2005;20:575-9.

30. Jessiman-Perreault G, McIntyre L. Household food insecurity narrows the sex gap in five adverse mental health outcomes among Canadian adults. Int $\mathcal{F}$ Environ Res Public Health 2019;16:319.

31. Melchior M, Caspi A, Howards LM, et al. Mental health context of food insecurity: a representative cohort of families with young children. Pediatrics 2009; 124:e564-72.

32. Bernard-Bonin AC; Mental Health and Developmental Disabilities Committee, Canadian Pediatric Society. Maternal depression and child development. Paediatr Child Health 2004;9:575-83.

33. Cummings EM, Davies PY. Maternal depression and child development. 7 Child Psychol Psychiatry 1994;35:73-112.

34. Nelson SE, Wilson K. The mental health of Indigenous peoples in Canada: a critical review of research. Soc Sci Med 2017;176:93-112.

35. Parpouchi M, Moniruzzaman A, Russolillo A, et al. Food insecurity among homeless adults with mental illness. PLoS One 2016;11:e0159334.

36. Pelletier L, O’Donnell S, Dykxhoorn J, et al. Underdiagnosis of mood disorders in Canada. Epidemiol Psychiatr Sci 2017;26:414-23.

Affiliations: Department of Pediatrics (Pound), Children's Hospital of Eastern Ontario; School of Epidemiology and Public Health (Chen), Faculty of Medicine, University of Ottawa, Ottawa, Ont.
Contributors: Catherine Pound conceptualized and designed the study, analyzed and interpreted the data, drafted the manuscript and revised it critically for important intellectual content. Yue Chen contributed to the study design and data interpretation, and revised the manuscript critically for important intellectual content. Both authors approved the final version to be published and agreed to be accountable for all aspects of the work.

Funding: There is no specific funding support associated with this study.

Data sharing: The data used in this study are available on request from the corresponding author.

Content licence: This is an Open Access article distributed in accordance with the terms of the Creative Commons Attribution (CC BYNC-ND 4.0) licence, which permits use, distribution and reproduction in any medium, provided that the original publication is properly cited, the use is noncommercial (i.e., research or educational use), and no modifications or adaptations are made. See: https://creativecommons.org/ licenses/by-nc-nd/4.0/.

Supplemental information: For reviewer comments and the original submission of this manuscript, please see www.cmajopen.ca/content/9/1/ E71/suppl/DC1. 